\title{
Duodenumda 5 yıl önce yutulmuş yabancı cisim: Olgu Sunumu
}

Foreign body in the duodenum that was swallowed 5 years ago: A case report

\section{Esin KORKUT ${ }^{1}$, Yaşar ÖZDENKAYA², Semih KORKUT ${ }^{3}$}

Medipol Üniversitesi Tip Fakultesi, ${ }^{1}$ Gastroenteroloji Bilim Dahl, ${ }^{2}$ Genel Cerrahi Anabilim Dah, Istanbul

Bakırköy Kamu Hastaneler Kurumu, ${ }^{3}$ Genel Sekreterliği, Istanbul

Yabancı cisim yutulması önemli morbidite ve mortaliteye neden olabilen bir durum olup, kesici delici yabanci cisimlerin acil endoskopik tedavisi gerekir. Bu makalede 5 yıl önce kaşık yuttuğunu bilen, girişim yapılmamış, 5 yıl sonra endoskopik olarak komplikasyonsuz çıkarılmış vakamızı sunmayı amaçladık.

Anahtar kelimeler: Yabancı cisim, duodenum, endoskopi

Yabancı cisim yutulması daha çok çocuklarda karşılaşılan bir durum olup daha az sıklıkla erişkin çağda; kronik alkoliklerde, epileptik veya psikiyatrik rahatsızlığı olanlarda ve zekâ geriliği olanlarda görülür. Yutulan cisimlerin yaklaşı \% 85’i mideden barsaklara ilerler ve hiçbir semptom oluşturmadan, vücuda zarar vermeden pasaj ile atılırlar (1). Bunun dışındaki hasta gruplarında endoskopik ya da cerrahi girişim gerekir. İki cm'den geniş ve altı cm'den uzun cisimler duodenum veya treitz bağında takılabilirler, endoskopik olarak çıkarılmalıdır$\operatorname{lar}(2)$.

Bu makalede 5 yll önce yutulmuş olan ve $10 \mathrm{~cm}$ uzunluğundaki kaşığın endoskopik olarak çıkarılmasını sunmayı amaçladik.

\section{OLGU SUNUMU}

Kırk iki yaşında erkek hasta yaklaşı 5 yıl önce alkollü iken kaşığın tutma kısmını yuttuğunu ve son zamanlarda aralıklı karın ağrısı yakınması olduğunu belirterek polikliniğimize başvurdu. Hastanın muayenesinde epigastrik bölgede hassasiyet mevcut olup, diğer sistem muayeneleri normaldi. Laboratuvar değerlendirmesinde kan sayımı ve biyokimyasal parametreler normaldi. Çektirilen ayakta direkt karın grafisinde duodenuma uyan bölgede olduğu düşünülen yabanc1 cisme ait radyoopak görünüm izlendi (Resim 1). Yapılan gastroskopisinde duodenum 3. kısım treitz bağına uyan bölgede yabancı cisim izlendi (Resim 2). Polipektomi sneari ile
The ingestion of foreign objects can cause significant morbidity and mortality. Sharp and pointed objects must be immediately removed through endoscopic treatment. In the present case, we describe the endoscopic removal of a spoon without any complication in an individual who had ingested the spoon 5 years ago, with no attempt of its removal being made since then.

Key words: Foreign body, duodenum, endoscopy

tutularak endoskopik olarak çıkarılan yabancı cismin $10 \mathrm{~cm}$ uzunluğunda sert cisim olduğu izlendi (Resim 3). Isslem sonrası 24 saat gözlem altında tutulan hastada ek sorun olmadı ve sorunsuz olarak taburcu edildi.

\section{TARTISMA}

Yabancı cisim yutulması en sık çocuklarda takiben yaşlılarda, psikotik vakalarda gözlenir. Tanı çoğunlukla hastadan alınan detaylı anamnez ve uygun görüntüleme yöntemi ile konulur. Fizik muayenede obstrüksiyon veya perforasyona bağlı bulgular olabileceği gibi tamamen normal de olabilir. Radyolojik görüntüleme yöntemleri yabancı cismin yerinin tespitinde yararlıdır. Düz grafi ile \%87 oranında yabancı cisim saptanabildiği bildirilmiştir (3).

Yutulan yabancı cisimlerin \%80-90'1 spontan olarak gaita ile atılabilmektedir. Ancak $2 \mathrm{~cm}$ 'den geniş, $6 \mathrm{~cm}$ 'den uzun yabancı cisimlerin mideden geçmesi çok nadirdir, bundan dolayı endoskopik olarak çıkarılmalıdır (4). Özellikle sivri cisimlerin çıkarımı esnasında yabancı cisimlerin mukozada hasar yaparak perforasyona yol açabildiği bildirilmiştir (5). Ucu sivri cisimlerin çılkarımı esnasında forseps ile sivri olmayan diğer kısımdan tutup çıkarmak veya overtube kullanmak perforasyon ihtimalini azaltabilir. Cisim çıkarılma esnasında üst özofagus sfinkteri düzeyinde forsepsten kurtulma olasillğına karşın bu bölgeden geçiş esnasında kontraksiyonsuz bir dönem gözetilebilir. 
Bizim vakamızda da kaşığın 6 cm'den uzun olması duodenumdan geçişi engellemiştir. Ilginç olarak 5 yıldır yabancı cisim çıkarılmamış olmasına rağmen herhangi bir komplikasyona yol açmamış, sadece son zamanlarda artmış olan aralıklı dispeptik yakınmalara yol açmıştır.

Sonuç olarak gastroskopi günümüz koşullarında yabancı cismin çıkarılması için en güvenilir yöntem olmaya devam etmektedir.

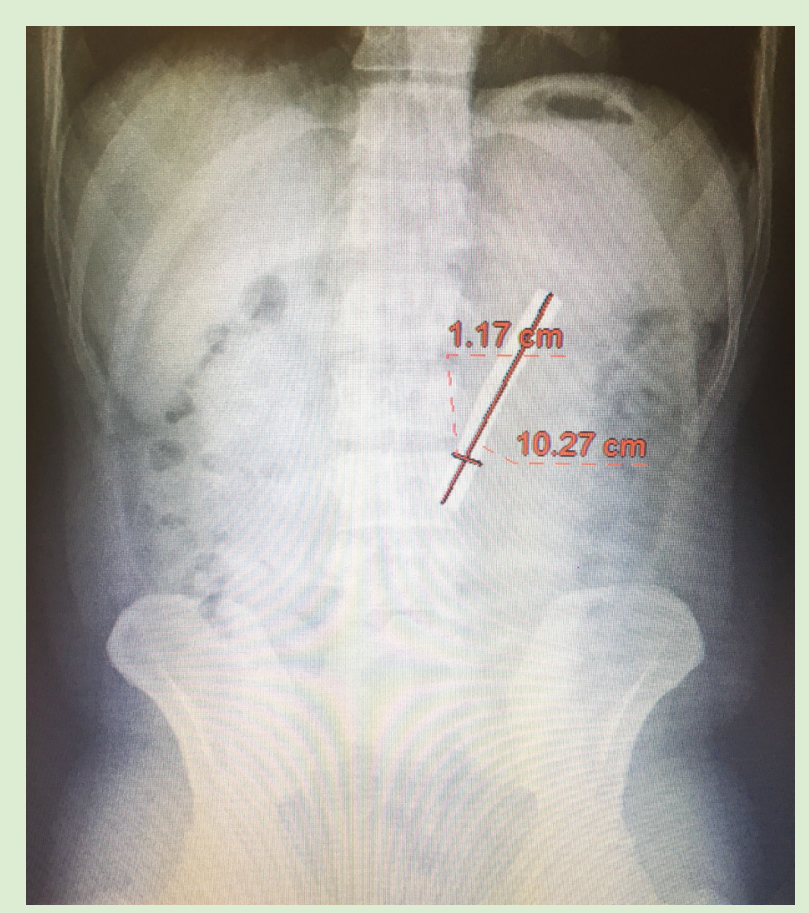

Resim 1. Ayakta direkt karın grafisinde yabancı cismin görünümü.

\section{KAYNAKLAR}

1. Bloom RR, Nakano PH, Gray SW, Skandalakis JE. Foreign bodies of the gastrointestinal tract. Am Surg 1986;52:618-21.

2. Guelfguat M, Kaplinskiy V, Reddy SH, DiPoce J. Clinical guidelines for imaging and reporting foreign bodies. AJR Am J Roentgenol 2014;203:37-53.

3. Ayantunde AA, Oke T. A review of gastrointestinal foreign bodies. Int J Clin Pract 2006;60:735-9.

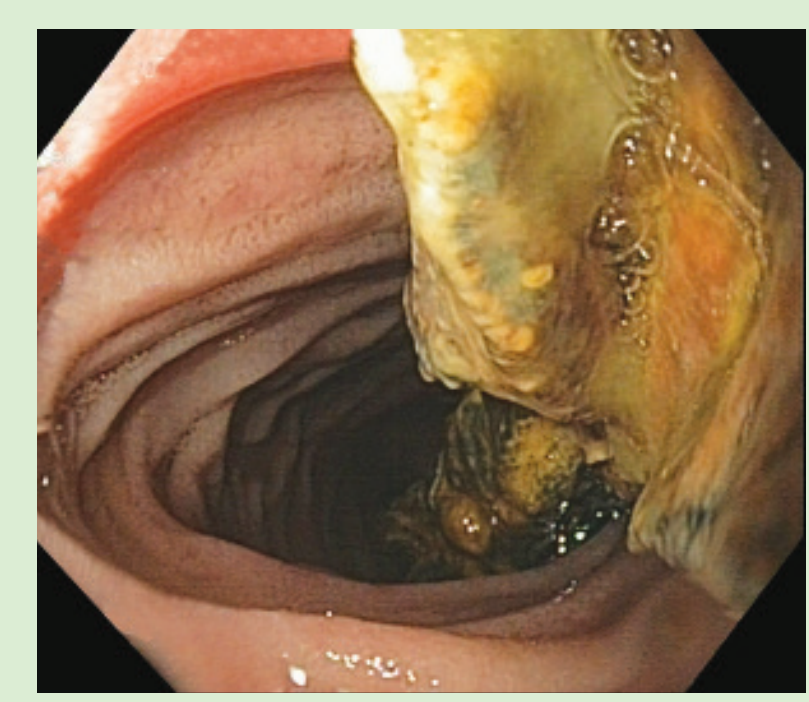

Resim 2. Duodenumda yabancı cismin gastroskop ile görünümü.

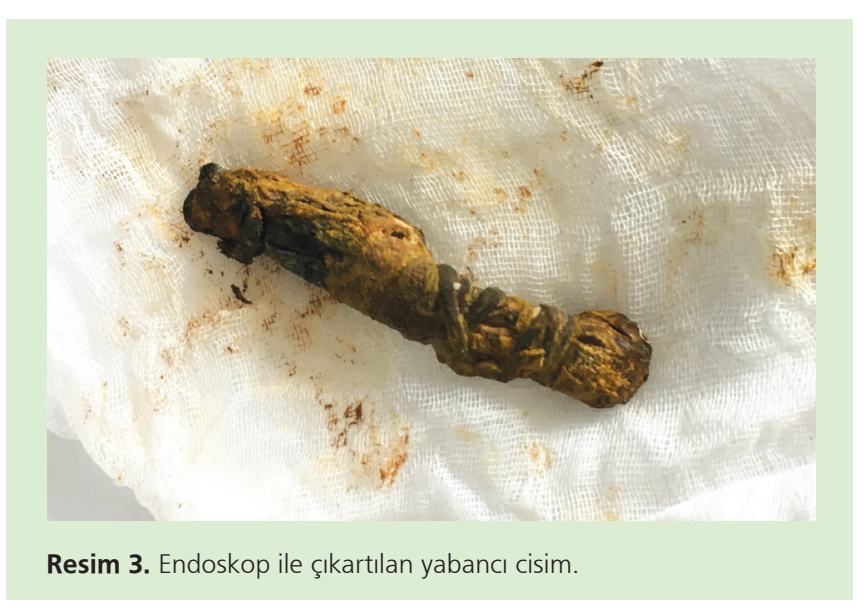

4. Webb WA. Management of foreign bodies of the upper gastrointestinal tract: update. Gastrointest Endosc 1995;41:39-51.

5. Classen M, Farthmann EF, Seifert E. Operative and therapeutic tecniques in endoscopy. Clin Gastroenterol 1978;7:741-63. 